\title{
Center of Experimental and Applied Cutaneous Physiology
}

The Center of Experimental and Applied Cutaneous Physiology (CCP) is situated at the Department of Dermatology and Allergology of Charité Hospital, the Medical Faculty of Humboldt University in Berlin.

Charité Hospital, originally founded in 1710 by the Prussian king Friedrich I as a plague hospital, is located in the center of Berlin. Charité Hospital became the Medical Faculty of Humboldt University in 1829.

The Department of Dermatology was founded by the renowned German dermatologist Friedrich Wilhelm Felix von Baerensprung in 1858 and today is one of the leading international institutions in the fields of medical care, research, and education.

In this setting in 1998, the CCP was founded with support of L'Oréal. The CCP is a European competence center for basic and applied research on cutaneous barrier function and on the human hair follicle and its regulation. Prof. Dr. Lademann, biophysicist, and Prof. Dr. Blume-Peytavi, dermatologist and hair researcher, both leading scientists in their field, direct the CCP. It is the aim of the CCP to catalyze a close interdisciplinary collaboration of dermatologists, physicians, bio- chemists, and biophysicists in the fields of skin and hair physiology. The activities are concentrated on basic and applied research. The CCP has a broad experience in conducting clinical and preclinical studies, based on certified quality management systems.

In the section of percutaneous absorption, noninvasive qualitative and quantitative in vivo methods are used to investigate the penetration kinetics of topically applied substances, e.g. sunscreens, drugs, and perfumes into the skin. In addition, the analysis of the penetration pathways (lateral spreading, follicle penetration, trans- and intercellular penetration) of topically applied substances in the human skin and model tissue is a main topic of research. The research activities are focused on the investigation of the correlation between penetration kinetics, the barrier function of the skin, and the effect of topically applied drugs and cosmetics. Furthermore, clinical and experimental studies are carried out to investigate the influence of topically applied substances on blood microcirculation.

The research activities in the section on molecular dermatology and the center for hair

\begin{tabular}{ll}
\hline KARGER & $\begin{array}{l}\text { (2) 2001 S. Karger AG, Basel } \\
\text { 1422-2868/01/0147-0002\$17.50/0 }\end{array}$ \\
$\begin{array}{l}\text { Fax +4161306 1234 } \\
\begin{array}{l}\text { E-Mail karger@karger.ch } \\
\text { www.karger.com }\end{array}\end{array}$ & $\begin{array}{l}\text { Accessible online at: } \\
\text { www.karger.com/journals/sph }\end{array}$
\end{tabular}


and hair diseases are concentrated on molecular and clinical research of human skin, the human hair follicle and related hair diseases. The projected research is directed towards the investigation of the complexity and the significance of regulatory signaling mechanisms in human skin and its appendages. Single cell populations of human skin and hair follicles, whole organ culture models as well as reconstructed epidermis are the tools available to investigate these regulatory mechanisms at the molecular level. The clinical and experimental research is focused on proliferation and differentiation processes in human skin and hair follicles, on programmed cell death and signaling pathways as well as on investigation of hair diseases.

A great number of experimental techniques, including analytical methods like la- ser scanning microscopy, electron microscopy, different spectroscopic methods, high pressure liquid chromatography, gas chromatography and investigation techniques like cell culture, organ culture models, blotting, immunoprecipitation, RT-PCR and others, are well-established techniques at the CCP.

The promotion of promising young scientists and mentoring is another declared aim of the CCP. Young scientists from different countries research in the CCP preparing dissertations or for their degree. Every year grants are awarded for innovative research projects in the field of skin physiology.

The CCP is the organizer of international workshops and conferences related to the topic of skin pharmacology and physiology and pathophysiology of hair diseases. 